\title{
Teaching Clinical Neuroscience to Psychiatry Residents: Model Curricula
}

\author{
John Coverdale • Richard Balon • Eugene V. Beresin • \\ Alan K. Louie • Glendon R. Tait • Michelle Goldsmith • \\ Laura Weiss Roberts
}

Received: 14 January 2014 / Accepted: 15 January 2014 / Published online: 4 February 2014

(C) Academic Psychiatry 2014

It has been proposed that the future of psychiatry is best grounded in the clinical neurosciences because advances in the assessment, treatment, and prevention of brain disorders are likely to originate from studies based on the clinical and translational neurosciences [1]. This exciting potential is reflected by the National Institute of Mental Health's strategic plan for research, which emphasizes the links between the neurosciences, genomics, and individual and public health outcomes [2]. Psychiatry trainees must therefore become skilled in being able to find, understand, critically appraise, and incorporate those advances that can meaningfully contribute to mental health and to the care of people living with mental illness.

Developing the requisite neuroscientific knowledge and skills for residents, however, is an especially challenging proposition for educators for several important reasons. First, there is a phenomenal rate of discovery and complexity of advances in the neurosciences and neuropsychiatry. Second, some programs are limited in the availability of faculty as well as trained educators in the neurosciences and neuropsychiatry. One early survey of program directors, for example, found that a lack of neuropsychiatric faculty was the most common

J. Coverdale $(\triangle)$

Baylor College of Medicine, Houston, TX, USA

e-mail: jhc@bcm.edu

R. Balon

Wayne State University, Detroit, MI, USA

E. V. Beresin

Harvard University, Boston, MA, USA

A. K. Louie $\cdot$ M. Goldsmith $\cdot$ L. W. Roberts

Stanford University, Stanford, CA, USA

G. R. Tait

University of Toronto, Toronto, ON, Canada reason for not providing neuropsychiatry training [3]. Last, but not least, our field has not yet really defined clinical neuroscience - a broad interdisciplinary domain that encompasses numerous areas and clearly much more than just neuropsychiatry. Much work remains to be done in characterizing clinical neuroscience, drawing connections between this basic, translational, and applied scientific field to the human aspects of human development, attachment, health, and healing that occur in the work of psychiatrists, and discerning what part of clinical or other neurosciences should be taught to residents, medical students, and our colleagues in the field (e.g., as a part of continuing medical education). Clarification of these issues should be the next step in making clinical neuroscience an integral part of what we teach.

One important response to the challenges presented by the acceleration of the field coupled with insufficiently prepared faculty is to develop well-designed neuroscience curricula that are portable across residency training programs. Our patients, as well as the field of psychiatry, will be best served when training programs work together to standardize learning objectives and curricula and to share the best educational practices [4]. To this end, this edition of Academic Psychiatry presents an exceptional compendium of articles concerning the education of psychiatry residents in the neurosciences [5-15]. One of these articles reported on a survey of residency training directors confirming the earlier finding [3] that a lack of qualified faculty constituted a barrier to training in the neurosciences and neuropsychiatry [12]. The vast majority of respondents in this survey identified a need for portable curricula [12]. In another survey, chief residents indicated that they did not feel adequately prepared to translate findings from neuroscience research into clinical practice [13]. Four of the articles [7, 9-11] described a neuroscience curriculum targeted to psychiatry residents. One commentary proposed a novel idea for a pilot training program based on the "triple board approach" [15]. 
Our primary goals for this editorial and review, therefore, are to identify and describe model curricula for educating psychiatry residents in the clinical neurosciences. We wanted to learn what topics were taught and how they were taught, and we also wanted to learn about individual curriculum designs and outcomes of teaching. Our intent is to describe key features of published curricula and to integrate the findings. By these methods, we hope to contribute to the sharing of information across programs and to promote the development of neuroscience training for psychiatry residents.

\section{Methods}

We searched for all English language and PubMed articles describing a general neuroscience-focused curriculum for psychiatry residents using combinations of search terms including neuroscience, neuropsychiatry, education, teaching, training, psychiatry, residents, and curriculum. We also hand searched the Academic Psychiatry from its inception in 1977 until its inclusion in the National Library of Medicine's electronic database (MEDLINE) in 2001, because this journal was thought to be the most likely repository of relevant articles, and we searched the citations of included articles for additional references as well. Articles were included whether or not any outcome data were provided. Articles were excluded when the curriculum was not specifically oriented toward psychiatry residents [16-20]. Two of these articles were introductory online teaching modules linking a clinical case to neuroscience concepts concerning the translation of neural circuits into novel therapeutics and fear/safety, anxiety, and anxiety disorders [17, 18]. A core curriculum for fellowship training in behavioral neurology and neuropsychiatry was also excluded [21]. We excluded a curriculum that was described as a weekly biological psychiatry seminar even though it included some topics in the neurosciences [22, 23]. We also excluded a description of weekly meetings between a resident and faculty member that served to construct neurobiological formulations [24]. Finally, we excluded articles that were focused on narrower, even though highly important, topic areas of neuropsychiatry such as neuroanatomy $[25,26]$ and neuroimaging [27].

We sought to describe individual programs in terms of the country of origin of the program and number of resident recipients and their year of training, the number of teaching sessions, and the topics and skills taught. We also sought to identify the methods and outcomes of teaching, as well as features pertinent to curriculum design. For this latter purpose, we used Oliva's comprehensive model of curriculum design [28], with its eight construction and design characteristics or principles (Table 1): scope, relevance, balance, integration, sequence, continuity, articulation, and transferability.
Table 1 Oliva's eight guiding questions for judging the curriculum

1. Is the scope of the curriculum adequate or realistic? Scope is defined as the sum of all activities or learning experiences, including the basic concepts and skills to be taught.

2. Is the curriculum relevant? Relevance is defined as the immediate and remote needs and interests of learners, as well as the relative merits of content whether abstract or concrete.

3. Is there balance in the curriculum? Balance is defined as the needs of society and the needs of the learner; cognitive, affective, and psychomotor domains; and group and individual experiences.

4. Is curriculum integration achieved? Integration is defined as the blending, fusion, or unification of disciplines under overarching themes or topics.

5. Is the curriculum properly sequenced? Sequence is defined as the order in which the elements of scope are arranged.

6. Is there continuity of programs? Continuity is defined as the planned repetition of content at successive levels, each time at an increased level of complexity.

7. Are curricula well articulated between levels? Articulation is defined as the meshing of the elements of the curriculum across levels of difficulty to provide smooth transitions for learners.

8. Is the learning of materials transferable? Transferability is defined as the transfer of affective, cognitive, and skills-based learning to new situations.

Adapted from Oliva [28]

\section{Results}

We found six articles that met our inclusion criteria [7, 9-11, $29,30]$. The six model curricula were US programs conducted at single sites, four of which were published in this issue of the journal [7, 9-11]. As can be seen in Table 2, four programs taught at one resident level $[7,9,29,30]$, and two taught across all years $[10,11]$. Class sizes ranged from about 7 to 18 , and for programs where data were available, the number of sessions per year ranged from about 8 to 45 . Disciplines represented by faculty included neurosurgery [29] and neurology, neuroradiology, toxicology, otorhinolaryngology, pharmacy, and pathology [11].

Most programs were taught predominantly by lectures [7, $9,10,29]$. One had residents directly contribute to that teaching [30], and another utilized an interactive paradigm that emphasized active learning principles [11]. A wide range of topics were taught (Table 2), including neuroanatomy, genetics, molecular biology, neurobiology, and neural systems including neural circuits, perception, learning and memory, case formulations, clinical dysfunctions, clinical neurology, social psychiatry, drug development, pharmacology, and other interventional approaches, constructing reviews, critical reading of the literature, current media depictions, and neuropsychiatry correlates, among others.

All of Oliva's eight principles for curriculum design were exampled by this set, sometimes several times across individual curricula. Examples of each of the principles are provided 
Table 2 Characteristics of model neuroscience curricula

\begin{tabular}{|c|c|c|c|c|c|c|}
\hline Authors & Class size & $\begin{array}{l}\text { Resident } \\
\text { levels }\end{array}$ & $\begin{array}{l}\text { No. of } \\
\text { sessions }\end{array}$ & Main method of instruction & Topics taught & $\begin{array}{l}\text { Method(s) of } \\
\text { evaluation }\end{array}$ \\
\hline $\begin{array}{l}\text { Lacy and Hughes } \\
\text { (2006) [29] }\end{array}$ & 12 & $3 \mathrm{rd}$ & 45 & Lecture & $\begin{array}{l}\text { Neuroanatomy, functional } \\
\text { neural systems, } \\
\text { pharmacology, clinical } \\
\text { neuropsychiatry }\end{array}$ & Post-course survey \\
\hline Dunstone (2010) [30] & 4 & 2nd & 20 & $\begin{array}{l}\text { Resident- and } \\
\text { faculty-taught } \\
\text { sessions }\end{array}$ & $\begin{array}{l}\text { Neuroanatomy, neurobiology, } \\
\text { molecular biology, perception, } \\
\text { learning and memory, genetics, } \\
\text { neurohormones, clinical cases }\end{array}$ & $\begin{array}{l}\text { Pre-/post-course } \\
\text { survey, clinical } \\
\text { literature review } \\
\text { as an exam }\end{array}$ \\
\hline Etkin et al. (2014) [7] & Not specified & 2nd & 25 & Lecture & $\begin{array}{l}\text { Neurobehavioral systems } \\
\text { (e.g., fear and extinction), } \\
\text { interventional approaches } \\
\text { (e.g., brain stimulation } \\
\text { therapies) }\end{array}$ & $\begin{array}{l}\text { Pre-/post-course } \\
\text { survey }\end{array}$ \\
\hline Griffith (2014) [9] & c. 7 & 2nd & 35 & Lecture & $\begin{array}{l}\text { Neuroanatomy and neural } \\
\text { circuitry, social, cognitive, } \\
\text { and existential neurosciences, } \\
\text { major psychiatric disorders }\end{array}$ & $\begin{array}{l}\text { Pre-/post-course } \\
\text { survey, } \\
\text { qualitative } \\
\text { data, exams }\end{array}$ \\
\hline $\begin{array}{l}\text { Gopalan et al. } \\
\text { (2014) [10] }\end{array}$ & $\begin{array}{l}\text { c. } 17 \text { per } \\
\text { year }\end{array}$ & $\begin{array}{l}\text { 1st, 2nd, } \\
\text { 3rd, 4th }\end{array}$ & Not specified & Lecture & $\begin{array}{l}\text { Introduction to the brain, } \\
\text { "brain at the bedside," } \\
\text { neurotransmission and } \\
\text { networking, advanced } \\
\text { clinical neurology }\end{array}$ & Post-course survey \\
\hline $\begin{array}{l}\text { Ross and Rohrbaugh } \\
\text { (2014) [11] }\end{array}$ & $\begin{array}{l}\text { c. } 18 \text { per } \\
\text { year }\end{array}$ & All & $\begin{array}{l}\text { c. } 18 \text { to } 33 \mathrm{~h} \\
\text { per year }\end{array}$ & Interactive paradigm & $\begin{array}{l}\text { Case formulations, "brain } \\
\text { camp," cases, neuroscientific } \\
\text { foundations }\end{array}$ & $\begin{array}{l}\text { Post-course survey, } \\
\text { qualitative data, } \\
\text { exam }\end{array}$ \\
\hline
\end{tabular}

below. One program undertook a needs assessment involving a task force of faculty from diverse clinical perspectives and residents in order to determine the scope of the curriculum and to set goals, which included that residents should appreciate the centrality of neuroscience to the future practice of psychiatry [11]. Balance was sought between neuroscience and "humanistic" components in one curriculum [9] and between the neuroscience curriculum and the rest of the residency curriculum [11]. Integration of the content in one program occurred across knowledge arising from animal and human works, pharmacological and psychosocial interventions, and individual and social processes [7] or by integrating the neurosciences with clinical cases in another program [30]. Sequence occurred both from the general to the particular and from introductory to more complex material [29] or by developing expertise in which new information was increasingly incorporated into a scaffold built on previous knowledge and experience [30]. Continuity was demonstrated by illustrating material at various points from introductory and overview sessions to presumably more complex ideas [29]. Articulation was described by a stepwise manner in which the curriculum was instituted over residency levels [10]. Transferability was illustrated by an examination testing how learning objectives were met when those questions assisted transfer of knowledge to critical reading skills [9].

All curricula evaluated their outcomes [7, 9-11, 29, 30] by post-course research designs $[10,11,29]$ or by pre-/post- course designs $[7,9,30]$ with additional qualitative data [9, 11] and examinations [9, 11, 30]. All of the curricula were evaluated positively. Residents perceived their knowledge to be adequate on completion of the course [29], gained confidence in finding and reading basic science articles [30], perceived that revising a course with a diagnostic to a research domain orientation was more practical and of higher quality [7], and rated lectures [10] and courses [11] well. Scores also improved on the Somatic Treatments subscale of the Psychiatry Resident-in-Training Examination [9]. Of note, in this same program [9], the residents listed their participation in grand rounds and conferences as stemming from interests stimulated by the neuroscience curriculum, and 3 of 20 residents entered the National Institute of Mental Health research fellowships.

\section{Discussion}

The publication of this journal issue with its special collection of papers on clinical neuroscience teaching represents a significant advance to the field of psychiatric education. Although it has been recommended that clinical neuroscience should become a core curriculum area in psychiatry [23] and although there is an increasing amount of neuroscience content in residency programs [31], we found that there was a 
relative dearth of published comprehensive model curricula before the publication of this edition. The four curricula published here [7, 9-11] will help to rectify this deficit. These comprehensively detailed educational resources together provide an outstanding set of resources for curriculum planners.

In order to bring clinical neuroscience teaching forward in the education of medical students and residents in psychiatry, goals and the specific curricular objectives for teaching the neurosciences should be developed. These goals and objectives in turn should reflect a thoughtful approach to how the neurosciences are conceptualized and defined. Similarly, they should reflect a very thoughtful approach to what should be taught. For example, a changing environment in medical education has led to a reassessment of assumptions and practices about what should be taught in neuroanatomy [32]. Although broad goals were described for these curricula, when defining a learning objective, a statement is required of (1) observable, behavioral outcomes, (2) criteria for successful performance of the behaviors, and (3) the situational context in which the behaviors are to be performed [28, 33]. We also need to learn more about the relative efficacy of teaching methods for imparting knowledge and skills. In particular, we need to learn about how to most efficaciously teach the skills of synthesizing and critically appraising newly published and potentially clinically relevant findings in the neurosciences.

We have emphasized here how it is important to assess the curriculum by the degree to which it implements basic principles of construction and organization. We have exampled how the six model curricula attempt to answer eight guiding questions central to curriculum design [28]. Any one curriculum is best judged, however, by assessing these guiding principles and their interrelationships together. In addition, the six curricula presented an evaluation of instruction which were consistently positive and encouraging to the educators. Moreover, the instructional assessments were used to feedback and modify various components of the curriculum including goal setting, selection of strategies for teaching, and the construction of particular elements of the curriculum.

The curricula in this special collection and those revealed in our literature search should be considered in the context of a wide number of educational resources, some of which have not yet undergone peer review but may be of value to our readers. Our search revealed educational components including electronic slide presentations and case-based rounds for trainees from developmental medicine, education, neurology, and psychiatry [16]; online modules [17, 18]; curricula proposals [8]; interdisciplinary neurobehavior rounds [20]; approaches for constructing neurobiological formulations [24]; as well as curricula on specific neuropsychiatry topics [25-27]. These and other resources [34, 35] will all contribute to the development of a national and international set of resources that will assist in developing the knowledge and skills of residents and practicing clinicians. One potential and very positive offshoot of this effort is that some residents might become inspired to undertake research in neuroscience or neuropsychiatry [9]. These curricula and related teaching resources should be considered alongside other strategies for developing a neuropsychiatry workforce. These strategies might include posting videos of each class session [11] or developing an award for resource-poor programs to fund prominent clinical neuroscience educators to visit and train the faculty and residents of those poorly resourced programs. The latter model has been applied to teaching psychodynamic psychotherapy [36]. Teaching should also be provided to faculty across clinical sites so that both residents and faculty will reinforce each others' learning.

Neuroscience is a complex, sometimes difficult to learn, and rapidly expanding interdisciplinary field that will severely challenge educators and curriculum designers. We therefore applaud our authors for promoting our understanding of education in the clinical neurosciences. The remarkable clinical neuroscience curricula identified here will contribute substantially to the transfer of information across programs and to developing the future generations of psychiatrists.

Disclosures The authors have no conflicts to disclose.

\section{References}

1. Reynolds III CF, Lewis DA, Detre T, et al. The future of psychiatry as clinical neuroscience. Acad Med. 2009;84:446-50.

2. Insel TR. Translating scientific opportunity into public health impact. A strategic plan for research on mental illness. Arch Gen Psychiatry. 2009;66:128-33.

3. Duffy JD, Camlin H. Neuropsychiatric training in American psychiatric residency training programs. J Neuropsychiatry Clin Neurosci. 1995;7:290-4.

4. Mongan E, Roca R. Impact of changes in psychiatric practice on psychiatric education in the USA. Int Rev Psychiatry. 2013;25:3118.

5. Chung J, Insel T. Mind the gap: neuroscience literacy and the next generation of psychiatrists. Acad Psychiatry. 2014. (in press).

6. Watson B, Michel R. Neuroscience in the residency curriculum: the psychoanalytic psychotherapy perspective. Acad Psychiatry 2014. (in press).

7. Etkin A, Cuthbert B. Beyond the DSM; development of a transdiagnostic psychiatric neuroscience course. Acad Psychiatry 2014. (in press).

8. Williams NR, Taylor JJ, Snipes JM et al. Interventional psychiatry; how should psychiatric educators incorporate neuromodulation into training? Acad Psychiatry 2014. (in press).

9. Griffith J. Neuroscience and humanistic psychiatry; a residency curriculum. Acad Psychiatry 2014. (in press).

10. Gopalan P, Azzam PN, Travis MJ, et al. Longitudinal interdisciplinary neuroscience curriculum. Acad Psychiatry 2014. (in press).

11. Ross D, Rohrbaugh R. Integrating neuroscience in the training of psychiatrists: patient-centered didactic curriculum based on adult learning principles. Acad Pscyhiatry 2014. (in press). 
12. Benjamin S, Travis MJ, Cooper JJ, et al. Neuropsychiatry and neuroscience education of psychiatry trainees: attitudes and barriers. Acad Psychiatry 2014. (in press).

13. Bennett J, Handa K, Mahajan, A Deotale P. Psychiatry chief resident opinions toward basic and clinical neuroscience training and practice. Acad Psychiatry 2014. (in press).

14. Fung L, Akil M, Widge A, et al. Attitudes toward neuroscience education among psychiatry residents and fellows. Acad Psychiatry 2014. (in press).

15. Anders TF, Roberts LW. Clinical neurosciences training for psychiatrists: one proposed model. Acad Psychiatry 2014. doi:10.1007/ s40596-014-0053-7.

16. Kitts RL, Christodoulou J, Goldman S. Promoting interdisciplinary collaboration: trainees addressing siloed medical education. Acad Psychiatry. 2011;35:317-21.

17. National Institute of Mental Health neuroscience and psychiatry modules. 2012a. Available at http://www.nimh.nih.gov/neuroscience-andpsychiatry-module/index.html. Accessed on 20 Dec 2013.

18. National Institute of Mental Health neuroscience and psychiatry modules: 2012b. Available at http://www.nimh.nih.gov/neuroscience-andpsychiatry-module2/index.html. Accessed on 20 Dec 2013.

19. Glick TH, Armstrong EG, Waterman MA, et al. An integrated preclerkship curriculum in neuroscience, psychiatry and neurology. Acad Psychiatry. 1997;21:212-8.

20. Matthews Jr MK, Koenigsberg R, Schindler B, et al. Neurobehavior rounds and interdisciplinary education in neurology and psychiatry. Med Educ. 1998;32:95-9.

21. Arciniegas DB, Kaufer DI. The joint advisory committee on subspecialty certification of the American Neuropsychiatric Association and the Society for Behavioral and Cognitive Neurology. J Neuropsychiatry Clin Neurosci. 2006;18:6-13.

22. Zisook S, Benjamin S, Balon R, et al. Alternate methods of teaching psychopharmacology. Acad Psychiatry. 2005;29:141-54.

23. Benjamin S. Educating psychiatry residents in neuropsychiatry and neuroscience. Int Rev Psychiatry. 2013;25:265-7.
24. Posner J, Stewart J, Rieder R. Neurobiological formulations: integrating clinical and biological psychiatry. Acad Psychiatry. 2007;31: 479-84.

25. Green R, Clark A, Hickey W, et al. Braincutting for psychiatrists: the time is ripe. J Neuropsychiatry Clin Neurosci. 1999;11:301-6.

26. Lane RD, Potter RL. Functional neuroanatomy of psychiatric disorders: a didactic course for residents. Acad Psychiatry. 2001;25:14855.

27. Downar J, Krizova A, Ghaffer O, Zaretsky A. Neuroimaging week: a novel, engaging, and effective curriculum for teaching neuroimaging to junior psychiatric residents. Acad Psychiatry. 2010;34:119 24.

28. Oliva PF. Developing the curriculum. 5th ed. NY: Longman; 2001.

29. Lacy T, Hughes JD. A neural systems-based neurobiology and neuropsychiatry course: integrating biology, psychodynamics, and psychology in the psychiatric curriculum. Acad Psychiatry. 2006;30: $410-5$.

30. Dunstone DC. Neurosciences-in-psychiatry curriculum project for residents in psychiatry. Acad Psychiatry. 2010;34:31-8.

31. Roffman JL, Simon AB, Prasad KM, et al. Neuroscience in psychiatry training: how much do residents need to know? Am J Psychiatry. 2006;163:919-26.

32. Hazelton L. Changing concepts of neuroanatomy teaching in medical education. Teach Learn Med. 2011;23:359-64.

33. Gall MD, Gall JP, Borg WR. Educational research: an introduction. 7th ed. Boston: Allyn \& Bacon; 2003.

34. Yudofsky SC, Hales RE. Essentials of neuropsychiatry and behavioral neuroscience. 2nd ed. VA: American Psychiatric Publishing; 2010.

35. Kandel ER, Schwartz JH, Jessell TM, et al. Principles of neural science. 5th ed. NY: McGraw Hill; 2013.

36. American Association of Directors of Psychiatric Residency Training and American Academy of Psychoanalysis and Dynamic Psychiatry Teichner Award. Available at www.aadprt.org. Accessed on 20 Dec 2013. 